\title{
Evidence of insecticide resistance selection in wild Anopheles coluzzii mosquitoes due to agricultural pesticide use
}

\author{
Chouaïbou Seïdou Mouhamadou ${ }^{1,2^{*}}$, Sarah Souline de Souza ${ }^{3}$, Behi Kouadio Fodjo ${ }^{1,4}$, Marius Gonse Zoh,6,7, \\ Nestor Kesse Bli ${ }^{1}$ and Benjamin Guibehi Koudou ${ }^{1,4}$
}

\begin{abstract}
Background: The wetlands used for some agricultural activities constitute productive breeding sites for many mosquito species. Thus, the agricultural use of insecticide targeting other pests may select for insecticide resistance in malaria mosquitoes. The purpose of this study is to clarify some knowledge gaps on the role of agrochemicals in the development of insecticide resistance in malaria vectors is of utmost importance for vector control.

Methods: Using the CDC bottle test and the log-probit analysis, we investigated for the first time the resistance levels of Anopheles coluzzii mosquitoes to neonicotinoids, insecticides used exclusively for crop protection in Côte d'Ivoire. The study was conducted in two agricultural regions (Tiassale and Gagnoa) and one non-agricultural region (Vitre) between June and August 2017 using clothianidin, acetamiprid and imidacloprid.

Results: Mosquito populations from Tiassale and Gagnoa (agricultural settings) were determined to be resistant to acetamiprid with mortality rates being $<85 \%$ at $24 \mathrm{~h}$ post-exposure. In Vitre (non-agricultural area) however, the mosquito population was susceptible to acetamiprid. In all three localities, mosquito populations were resistant to imidacloprid (mortality rates were $60 \%$ in Vitre, 37\% in Tiassale, and $13 \%$ in Gagnoa) and completely susceptible to clothianidin (100\% mortality). An. coluzzii represented 100\% of mosquito collected in Gagnoa, $86 \%$ in Tiassale and $96 \%$ in Vitre.

Conclusions: This study provides strong evidence that agricultural use of insecticides can cause insecticide resistance in malaria vector populations. Insecticide resistance driven by agrochemical usage should be considered when vector control strategies are developed.
\end{abstract}

Keywords: Vector control, Insecticide resistance, Resistance selection, Agriculture, Anopheles coluzzii

\section{Multilingual abstracts}

Please see Additional file 1 for translations of the abstract into the five official working languages of the United Nations.

\section{Background}

The precipitous rise in insecticide resistance among disease vectors makes the development of new insecticides for vector control important now more than ever. There

\footnotetext{
* Correspondence: mouhamadou.chouaibou@csrs.ci

${ }^{1}$ Centre Suisse de Recherches Scientifiques en Côte d'Ivoire (CSRS), Abidjan, Côte d'Ivoire

${ }^{2}$ Department of Entomology and Plant Pathology, North Carolina State University, Raleigh, NC, USA

Full list of author information is available at the end of the article
}

are a range of insecticide classes used in agriculture that have not yet been applied to public health, such as the neonicotinoids. Some of these likely will provide additional modes of action for insecticide resistance management, particularly until new modes of action dedicated to vector control become available.

The neonicotinoid family is composed of eight active ingredients which includes imidacloprid, thiamethoxam, thiacloprid, nitenpyram, acetamiprid, clothianidin, dinotefuran and nithiazine. These have a unique mode of action from other insecticides currently used in public health, hence their potential value in resistance management. They act by selectively targeting the invertebrate nicotinic acetylcholine receptor (nAChR) and disrupting

(C) The Author(s). 2019 Open Access This article is distributed under the terms of the Creative Commons Attribution 4.0 International License (http://creativecommons.org/licenses/by/4.0/), which permits unrestricted use, distribution, and 
excitatory cholinergic neurotransmission leading to paralysis and death [1]. Neonicotinoids are widely used in agriculture. Their pest spectrum, systemic activity and relatively low risk to non-target organisms have resulted in their widespread use. They constituted more than $25 \%$ of the insecticides sold globally in 2014 [2]. Imidacloprid, the first neonicotinoid developed for commercial use, was introduced in 1991. While it is currently the most widely-used neonicotinoid, several others have been developed and implemented since its inception.

Interest in neonicotinoids for vector control is focused around clothianidin, which was developed by both Sumitomo (solo, under the brand name SumiShield) and Bayer (as a combination with deltamethrin, under the brand name Fludora Fusion). These lead to a need to better understand the current susceptibility profiles of Anopheles spp. malaria mosquitoes to this family of compounds, especially in areas where agricultural usage is high. Several studies have proposed the link between agricultural pesticide use and the development of insecticide resistance in malaria vectors [3-8], although direct causal links have been difficult to establish, as these studies focused on insecticide modes of action that are used both in agriculture and in public health.

In the study described herein, neonicotinoids were never involved in any vector control strategy in Côte d'Ivoire, so any potential resistance observed in Anopheles spp. vectors to these products could only be attributed to their use in agriculture. Three neonicotinoids were assessed in this study: clothianidin, acetamiprid and imidacloprid. We sought to evaluate, for the first time, the resistance level of natural malaria vectors to neonicotinoids in different agrochemical use contexts, and to generate data that could serve as a basis for discussion of novel neonicotinoidbased vector control strategies. Addressing these also will clarify important knowledge gaps on the role of agrochemicals in the development of insecticide resistance in malaria vectors and implications for malaria vector control interventions.

\section{Methods}

\section{Study sites}

The study was conducted at three different geographical areas: Vitre $\left(5^{\circ} 15^{\prime} 44^{\prime \prime} \mathrm{N}, 3^{\circ} 45^{\prime} 14^{\prime \prime} \mathrm{W}\right)$ ), Tiassale $\left(5^{\circ} 53^{\prime} 54^{\prime \prime}\right.$ $\left.\mathrm{N}, 4^{\circ} 49^{\prime} 42^{\prime \prime} \mathrm{W}\right)$ and Gagnoa $\left(6^{\circ} 08^{\prime} 00^{\prime \prime} \mathrm{N}, 5^{\circ} 56^{\prime} 00^{\prime \prime} \mathrm{W}\right)$ in Côte d'Ivoire, that varied by agricultural profile (i.e. the main crops grown in that area) and the subsequent use of agrochemicals. Vitre is a peri-urban area located $30 \mathrm{~km}$ to the southeast of Abidjan, the economic capital of Côte d'Ivoire. Its climate is tropical, with a short dry season, and a rainy season marked by high rainfall most months of the year (average precipitation of $1912 \mathrm{~mm}$ of rain) and an average temperature of $26.5^{\circ} \mathrm{C}$. Food production, which is the main agricultural activity of the region is not as practiced as lagoon fishing which constitutes the main economic activity of residents. Gagnoa is located approximately at $270 \mathrm{~km}$ northeast of Abidjan. The prevailing climate is humid tropical and has four seasons including a long rainy season followed by a short dry season, and then a short rainy season followed by a long dry season. Temperatures range from 21 to $35^{\circ} \mathrm{C}$ during the year. Gagnoa is located in a densely forested area, which is now severely degraded by the ubiquitous cacao crop; together with cassava constitutes the main economic activity of the region. Other agricultural activities include growing maize, yams, rice, coffee, plantain and other food products. A pervasive use of pyrethroids and neonicotinoids has been recorded in this region in crop protection (primarily against cocoa pests). These two insecticide classes account for more than $90 \%$ of all insecticides used in the region [9]. Tiassale is located between Abidjan and Gagnoa in southern Côte d'Ivoire, about $120 \mathrm{~km}$ northwest of Abidjan. The climate is tropical and also characterized by four seasons. A long rainy season during which falls $2 / 3$ of the annual rainfall, a short dry season, then a short rainy season followed by a long dry season. Tiassale is a rice-growing irrigated area with an intensive use of agrochemicals throughout the year including pyrethroids accounting for approximately $85 \%$, and neonicotinoids accounting for approximately $9 \%$ of all agrochemicals used [4].

\section{Field sampling}

The study was conducted between June and August 2017 corresponding to the rainy season favourable to breeding site creation. Mosquito larvae were sampled from multiple breeding sites at each locality and pooled together, then re-distributed evenly in development trays containing fresh water. They were provided access to powdered TetraFin ${ }^{\circ}$ fish food, and were reared to adults under insectary conditions of $25-28{ }^{\circ} \mathrm{C}$ and $70-80 \%$ relative humidity (RH) at the Centre Suisse de Recherches Scientifiques en Cote d'Ivoire. Adults were maintained in $35 \mathrm{~cm}^{3}$ cages and allowed access to $10 \%$ sugary water.

\section{CDC bottle bioassays}

\section{Determination of neonicotinoids diagnostic doses}

The determination of a diagnostic concentration was made using bottle bioassays. The treatment of bottles was conducted in compliance with US Center for Disease Control (CDC) guidelines [10, 11]. Acetamiprid used was formulated as Optimal 20SP whereas imidacloprid and clothianidin were technical materials. These chemicals were obtained from Bayer CropScience Ltd. Each chemical was mixed in acetone (or acetone and Mero for clothianidin) at different concentrations ranging from 50 to $200 \mu \mathrm{g} / \mathrm{bottle}$ and used for testing against the susceptible An. gambiae Kisumu mosquitoes 
to determine the diagnostic concentration. The diagnostic concentration was defined as the minimum concentration that killed $100 \%$ of susceptible mosquitoes after 0.5-1 h exposure and a $24 \mathrm{~h}$ holding period.

\section{Assessment of the insecticide resistance level}

The bioassays were performed with bottles in an upright position according to CDC guidelines [10] using 20 to 25 non-blood-fed, wild adult female An. gambiae sensu lato mosquitoes, 3 to 5 days old. Four replicates were tested per condition (Additional files 2, 3 and 4). During the exposure period, knocked down mosquitoes (mosquito lies on its back, mosquito that cannot stand, mosquito that cannot fly in coordinate manner and mosquito that can take off briefly but falls down immediately) were counted every $5 \mathrm{~min}$ (Additional files 2, 3 and 4). After the corresponding exposure time defined with the susceptible strain, mosquitoes were removed from the bottles and placed into net-covered plastic cups containing a $10 \%$ honey solution. They were observed for mortality daily for five consecutive days (Additional files 2, 3 and 4). Testing was performed at $25-27^{\circ} \mathrm{C}$ and 70-90\% RH.

\section{Molecular identification of mosquitoes DNA extraction}

A total of 50 adult mosquitoes from the negative control batches were processed for molecular identification. Genomic DNA of whole mosquitoes was extracted according to Collins et al. [12]. In brief, whole mosquitoes previously soaked individually in $200 \mu \mathrm{l}$ of $2 \%$ cetyl trimethyl were crushed and incubated at $65^{\circ} \mathrm{C}$ for $5 \mathrm{~min}$. Then, $200 \mu \mathrm{l}$ of chloroform was added and the resulting mixture was centrifuged for $5 \mathrm{~min}$ at $12000 \mathrm{rpm}$. The supernatant was pipetted into a new $1.5 \mathrm{ml}$ tube to which $200 \mu \mathrm{l}$ isopropanol was added; DNA was precipitated by spinning the mixture for $15 \mathrm{~min}$ at $12000 \mathrm{rpm}$. The supernatant was removed and the pellet of DNA formed at the bottom of tubes was purified with $70 \%$ ethanol. A further centrifugation step at $12000 \mathrm{rpm}$ for 5 min was used to rinse the DNA, the excess ethanol was removed, and the resulting pellet was dried on the lab bench overnight. The extracted DNA was reconstituted in $20 \mu \mathrm{l}$ DNase-free water (Sigma-Aldrich, United Kingdom) prior to storage at $-20^{\circ} \mathrm{C}$.

\section{Identification of Anopheles gambiae complex members}

Specimens were identified to species by Sine polymerase chain reaction (PCR) [13]. PCR reactions were carried out in a $25 \mu \mathrm{l}$ reaction which contained 1 pmol of each of the following primer: F6.1A of sequence 5'-TCGCCTTAGACCTTGCGTTA-3' used to determine $A n$. coluzzii formerly known as $A n$. gambiae $\mathrm{M}$ molecular form and the R6.1B of sequence 5'-CGCTTCAAGAATTCGAGATAC-3' for An. gambiae formerly known as An. gambiae S molecular form. The other reagents included $0.2 \mathrm{mmol} / \mathrm{L}$ of each dNTP, $1.5 \mathrm{mmol} / \mathrm{L} \mathrm{MgCl}_{2}, 2.5 \mathrm{U}$ Taq polymerase, and $1 \mu \mathrm{l}$ of DNA template extracted from individual mosquitoes. The thermocycler program was: $94{ }^{\circ} \mathrm{C}$ for $5 \mathrm{~min}$ followed by 35 cycles of $94{ }^{\circ} \mathrm{C}$ for $25 \mathrm{~s}, 54{ }^{\circ} \mathrm{C}$ for $30 \mathrm{~s}$ and $72{ }^{\circ} \mathrm{C}$ for $1 \mathrm{~min}$, a final elongation step at $72{ }^{\circ} \mathrm{C}$ for $10 \mathrm{~min}$, and a $4{ }^{\circ} \mathrm{C}$ hold. The resulting products were allowed to migrate on a $1.5 \%$ agarose gels stained with ethidium bromide. The profile of the expected bands by species was $479 \mathrm{bp}$ for An. coluzzii and $249 \mathrm{bp}$ for $A n$. gambiae s.s. after visualization with an ultra violet illuminator.

\section{Test data interpretation}

Test data were interpreted based on World Health Organization (WHO) criteria [14], stating that: mortality $<90 \%$ is indicative of resistance, mortality levels from 90 to $97 \%$ is suggestive of probable resistance and needs further investigation, and mortality $\geq 98 \%$ is indicative of susceptibility. The mortality of a test sample was calculated by summing the number of dead mosquitoes across all four exposure bottles and expressing this as a percentage of the total number of exposed mosquitoes. The Abbott formula [15] was used to correct test mortality if mortality in the control was $5-20 \%$. The test was repeated if mortality in the control was more than $20 \%$. The time necessary to allow $50 \%$ of test mosquito populations to be knocked down $\left(\mathrm{KDT}_{50}\right)$ was determined using the PoloPlus software 1.0 (Leora Software Services, Northampton Business Center, Northampton, UK).

via log-probit analysis, and the Resistance Ratio (RR) calculated as the $\mathrm{KDT}_{50}$ of the wild strain divided by the $\mathrm{KDT}_{50}$ of the susceptible Kisumu strain.

\section{Results \\ Diagnostic doses}

It appeared that $50 \mu \mathrm{g} /$ bottle of clothianidin, $75 \mu \mathrm{g} / \mathrm{bottle}$ of acetamiprid, and $200 \mu \mathrm{g} / \mathrm{bottle}$ of imidacloprid were the minimum concentrations that caused $100 \%$ mortality on the susceptible Kisumu strain at $24 \mathrm{~h}$ post-exposure after a minimum of $30 \mathrm{~min}$ exposure for clothianidin and $1 \mathrm{~h}$ exposure for both acetamiprid and imidacloprid in CDC bottles. They were therefore considered as diagnostic concentrations for the entirety of the study.

\section{Knockdown and resistance ratio}

Knocked down mosquitoes were recorded for both acetamiprid and imidacloprid insecticides tested in the three localities, which rendered possible the determination of Resistance Ratios (RR), (Table 1). With regard to clothianidin, we were unable to determine the time needed for $50 \%$ of the population to be knocked down, as more 
Table 1 Resistance ratio of wild Anopheles coluzzii populations from non-agricultural (Vitre) and agricultural areas (Tiassale and Gagnoa) exposed to three neonicotinoids

\begin{tabular}{lllll}
\hline Localities & Insecticides & \multicolumn{2}{l}{ KDT50 (95\% Cl) in minutes } & Resistance ratio* \\
\cline { 3 - 4 } & & Kisumu & Wild strains & 1.130 \\
\hline Vitre & Acetamiprid & $13.7(10.47-16.68)$ & $15.52(13.6-18.013)$ & 5.747 \\
Tiassale & Imidachloprid & $18.2(14.95-21.88)$ & $104.6(77.2-197.7)$ & 1.526 \\
& Acetamiprid & $13.7(10.47-16.68)$ & $20.9(14.14-25.7)$ & 6.132 \\
Gagnoa & Imidachloprid & $18.2(14.95-21.88)$ & $111.6(78.3-247.4)$ & 1.062 \\
& Acetamiprid & $13.7(10.47-16.68)$ & $15.7(11.6-19.07)$ & 1 knock down only after $1 \mathrm{~h}$ \\
\hline
\end{tabular}

$\mathrm{KDT}_{50}$ : The time necessary to allow $50 \%$ of test mosquito populations to be knocked down. Determined using the PoloPlus software 1.0 via log-probit analysis *Resistance ratio (RR) calculated as the $\mathrm{KDT}_{50}$ of the wild strain divided by the $\mathrm{KDT}_{50}$ of the susceptible Kisumu strain +++ could not be calculated, indefinite

than $90 \%$ mosquitoes dead in less than 15 min exposure to this chemical and did not allow generation of sufficient data points for a regression curve. For acetamiprid, the $\mathrm{TKD}_{50}$ of the Kisumu susceptible strain was 13.74 (95\% CI: 10.47-16.08) min. This time has slightly increased among the wild mosquito populations. However, the RR remained at $<2$ for the three locations (Fig. 1a). As for imidacloprid, the $\mathrm{TKD}_{50}$, which was 18.25 (95\% CI: $14.94-21.88$ ) $\mathrm{min}$ in the Kisumu strain, increased to 104.6 (95\% CI: 77.2-197.7) min among the nonagricultural area of Vitre mosquito populations, and
111.6 (95\% CI: 78.3-247.4) $\mathrm{min}$ in the rice cultivation area of Tiassale. Only one mosquito was knock down at the cocoa area of Gagnoa. This resulted in an RR varying from 5.747 for Vitre to 6.132 in Tiassale and indefinite in Gagnoa (Fig. 1b).

\section{Mortality}

The mosquito populations from the three localities were completely susceptible to clothianidin, as there was $100 \%$ mortality at $24 \mathrm{~h}$ after $30 \mathrm{~min}$ of exposure (Fig. 2). The mosquito populations from Tiassale and Gagnoa

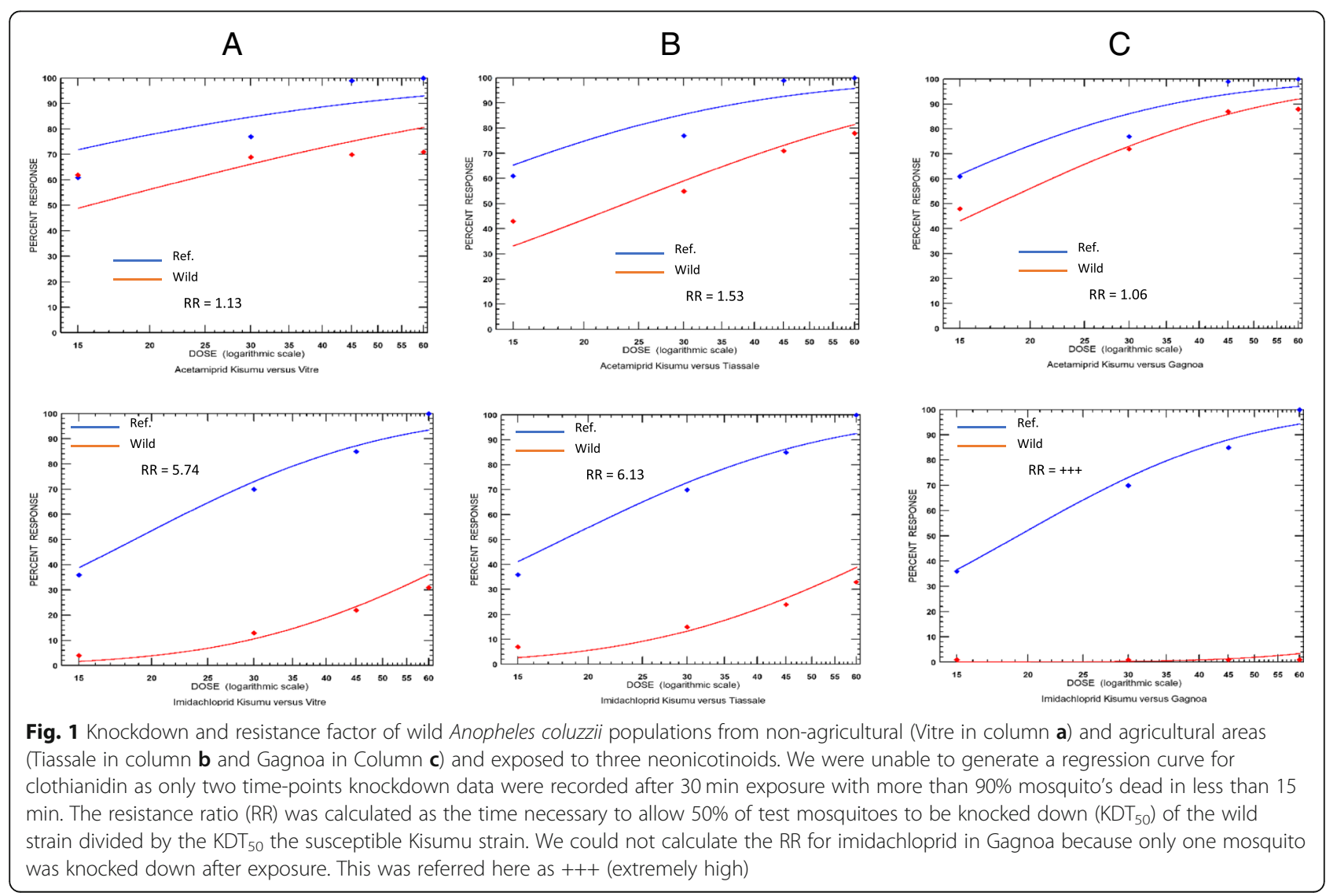




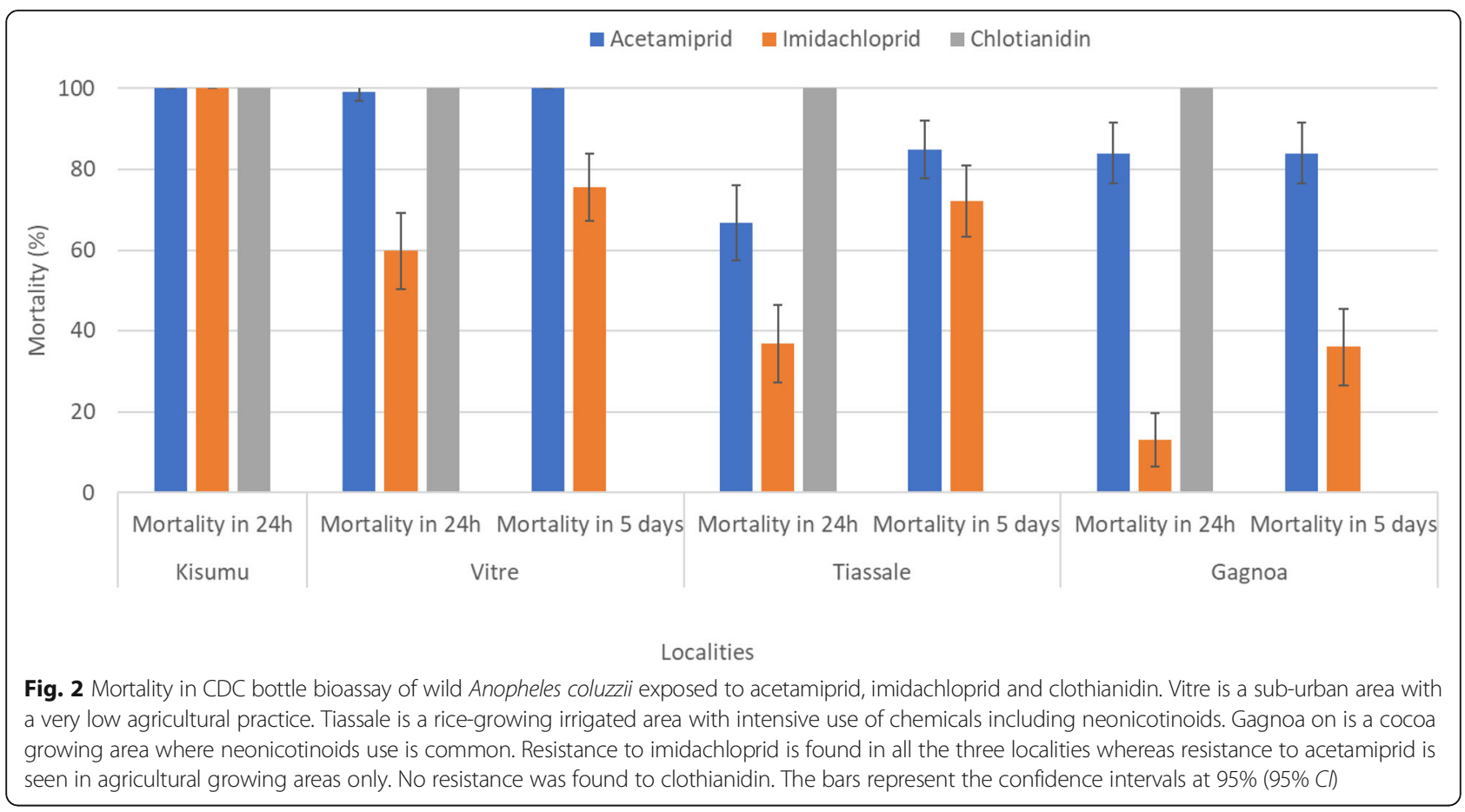

appeared to be resistant to acetamiprid with mortalities less than $85 \%$ even 5 days post-exposure. In Vitre however, mosquitoes displayed $99 \%$ mortality after $24 \mathrm{~h}$ post exposure thus reflecting complete susceptibility (Fig. 2). Concerning imidacloprid, the mosquito populations were resistant to this compound in the three localities (Fig. 2). The highest mortality was recorded in Vitre followed by Tiassale, and the lowest observed in Gagnoa. Mortalities after $24 \mathrm{~h}$ post-exposure decreased from $60 \%$ in Vitre, non-agricultural area, to $37 \%$ in Tiassale and $13 \%$ in Gagnoa, both agricultural settings. After 5 days, mortalities at the three localities were still less than $75 \%$.

\section{Species identification}

A total of 50 female mosquitoes were characterized per locality for species identification. It appeared that all individuals from Gagnoa were identified as An. coluzzii (100\%), in Tiassale $86 \%$ of the mosquitoes were $A n$. coluzzii (43 individuals were $A n$. coluzzii and six were An. gambiae) and in Vitre $96 \%$ of the mosquitoes were An. coluzzii (48 individuals) and 4\% (two individuals) were hybrids of $A n$. coluzzii and An. gambiae.

\section{Discussion}

The present study explores for the first-time resistance to neonicotinoids in the principal malaria vector $A n$. gambiae. It raises the question of the importance of the impact of insecticides used in agriculture on the development of resistance in insects of public health interest. Indeed, the neonicotinoids are compounds exclusively used in agriculture. In Côte d'Ivoire, imidacloprid and acetamiprid are widely used for cocoa crop protection [9], and to a considerable extent in the protection of rice fields against pests [4]. The fact that they have never been used in public health suggests that they may have triggered the observed resistance in Anopheles. According to Lines [16], for an insecticide used in agriculture to be the source of insecticide resistance selection in public health insects, resistance to this compound should be observed before its use for vector control and the level of resistance should be high in areas where this compound is used compared to areas where only vectorbased treatments are available. However, multipleresistance, which encompasses neonicotinoids and other agrochemicals, is also a possibility as these insecticides are used in a program that includes applications of herbicides and fungicides. The subsequent exposure of mosquito populations to multiple biocides might select for several metabolic pathways with a putative side effect on tolerance to a broader range of insecticides, including neonicotinoids. In other insects, resistance to neonicotinoids involves either a modification of the insecticide target site, preventing the insecticide from reaching its site of action following a gene polymorphism, or an increase in the degradation of the insecticide by metabolic enzymes. The neonicotinoid insecticides kill by disrupting the normal physiological workings of the nicotinic acetylcholine receptor ( $\mathrm{nAChR}$ ), which is a ligand-gated ion channel responsible for mediating excitatory cholinergic neurotransmission in the central nervous system of invertebrates [1]. The first incidences of resistance to neonicotinoids appeared 5 years after their 
introduction around 1996, in a worst case scenario in glasshouse production systems where multiple insecticide applications occurred within a finite pest population that also had a high reproductive rate. Today, resistance to these products is present in a substantial number of pests and the Arthropod Pesticide Resistance Database lists more than 500 cases of resistance to neonicotinoids [17].

Mutations on the $\mathrm{nAChR}$ responsible for neonicotinoid resistance appear to be very rare in nature [2], but when individuals are subjected to extensive selection pressures under laboratory conditions, mutations on these receptors associated with resistance are observed. Cloning of nAChR subunits of Nilaparvata lugens, the brown planthopper, after selection pressure with imidacloprid over 35 generations in laboratory conditions revealed that a replacement of tyrosine with a serine was associated with a 250-fold resistance level to imidacloprid [18]. Another mutation on nAChR corresponding to an arginine to threonine substitution, also known as an R81T mutation, was described as the first proven case of target-site modification leading to control failure of Myzus persicae, the green peach aphid, with neonicotinoids under field conditions [19]. Metabolic resistance appears to be much more common [2, 20]. Elevated expression levels of glutathione-S-transferases and esterases have been associated with resistance to Diaphorina citri [21] and Aphis gossypii [22]. Over expression of P450s monoxygenases are also frequently reported in many resistant cases. Enhanced expression level of this enzyme family has been strongly associated with resistance to neonicotinoids in $M$. persicae [23], Bemisia tabaci [24-26], Trialeurodes vaporariorum [27], Nilaparvata lugens [28], Leptinotarsa decemlineata [29] and many other pests [2]. Since the purpose of this study was to monitor for the first time the resistance level to neonicotinoids in Anopheles vectors, we did not consider investigating the different mechanisms involved in this resistance, which can appear as a limitation to the study. However, bioassays with synergists can provide a quick and easy basis for initial characterization of neonicotinoid resistant mosquito populations.

The sharp rise in insecticide resistance is, among other factors, favoured by the limited number of vector control insecticides which results in excessive use of the same products. Consequently, this leads to an increase in selection pressure on the targeted individuals; hence the need for new molecules with different modes of action. The time required to develop completely new compounds is extremely long so the reformulation of insecticides currently used in agriculture remains an attractive option; however, this must take into account the pressure that already exists because of the use of these molecules in agriculture. Therefore, mixture or combination formulations should be prioritized over simple formulations in order to preserve long-term efficacy and a greater impact on malaria. That is, given the assumption that the compounds could act in synergy, or that each insecticide in the mixture will be able to eliminate those individuals that are susceptible to it [30].

Beyond that, vector control needs to be rethought or reimagined with the introduction of new mechanistic tools or interventions or strategies that go beyond mosquito nets and indoor residual spray, and that take into account local specificities. For instance, sub-Saharan African countries have intense agricultural production, and farming represents the primary source of food and/or income [31]. The use of chemicals is the principal pest control strategy commonly applied by farmers to protect their investment [31]. This can appear as an advantage for vector control. Given that swamp and wetlands used for some agricultural activities also constitute productive breeding sites for many mosquito species, agricultural pest control may become an important vector control strategy operated by farmers themselves. Indeed, the importance of larvicides in vector control programs is well known, but because its implementation involves complicated logistics and efforts to be effective, it has very often led to its abandonment. If some agricultural pesticides are reformulated and combined with selected biological larvicides, their use by the farmers could both protect their crops and control vector larvae. This approach was recently tested in Cote D'Ivoire (Chouaibou et al., in prep.) and may possess several advantages as no additional effort would be required from the farmer. In addition, savings would be made on logistics and efforts that should have been deployed by public health actors if they were to implement larviciding. Moreover, the routine nature of pesticide use in agriculture should ensure the effectiveness of the approach and it will boost traditional vector control (use of mosquito nets and indoor spraying) by attacking another link in the mosquito development chain, the larva. Such integrated pest and vector control management should be considered in depth and implemented.

\section{Conclusions}

The findings herein provide evidence that the use of chemicals in agriculture can trigger insecticide resistance in malaria vectors. Thus, strategies to overcome the problem of resistance to insecticides in malaria vectors should take into account the major sources of resistance and be designed to delay its appearance. Data generated here could serve as a basis for the discussion of novel neonicotinoid-based vector control interventions.

\section{Additional files}

Additional file 1: Multilingual abstracts in the five official working languages of the United Nations. (PDF $500 \mathrm{~kb}$ ) 
Additional file 2: BOTTLE TEST RESULTS SHEET of Anopheles coluzzii from Gagnoa. (XLS 49 kb)

Additional file 3: BOTTLE TEST RESULTS SHEET of Anopheles coluzzii from Vitre. (XLS $54 \mathrm{~kb}$ )

Additional file 4: BOTTLE TEST RESULTS SHEET of Anopheles coluzzil from Tiassale. (XLS $52 \mathrm{~kb}$ )

\section{Abbreviations}

CDC: Centers for Disease Control; DNA: Deoxyribonucleic acid; KDT: Knock down time; Min: Minute; nAChR: Nicotinic acetylcholine receptor; PCR: Polymerase chain reaction; RR: Resistance ratio; WHO: World Health Organization

\section{Acknowledgments}

We thank CSRS staff and all the people who helped to edit this article.

\section{Authors' contributions}

CSM conceived the study and design the protocols, analysed the data and drafted the manuscript. SSS help designing the study, revised protocol and edited the manuscript. BKF, MGZ and NKB carried out the field sampling, mosquito rearing, bioassays and data collections. BGK edited and improved the manuscript. All authors read and approved the final manuscript.

\section{Funding}

This work was supported by Wellcome Trust (No. 103995); and Bayer

Cropscience Ltd.

\section{Availability of data and materials}

All data generated or analysed during this study are included in this published article [and its supplementary information files].

\section{Ethics approval and consent to participate}

Not applicable.

\section{Consent for publication}

Not applicable.

\section{Competing interests}

The authors declare that they have no competing interests.

\section{Author details}

${ }^{1}$ Centre Suisse de Recherches Scientifiques en Côte d'Ivoire (CSRS), Abidjan, Côte d'Ivoire. ${ }^{2}$ Department of Entomology and Plant Pathology, North Carolina State University, Raleigh, NC, USA. ${ }^{3}$ Bayer West-Central Africa SA, Abidjan, Côte d'Ivoire. ${ }^{4}$ Université Nangui Abrogoua, Abidjan, Côte d'Ivoire. ${ }^{5}$ Laboratoire d'Ecologie Alpine (LECA), CNRS, Grenoble, France. ${ }^{6}$ Université Grenoble-Alpes, Grenoble, France. ${ }^{7}$ Environmental and Systems Biology (BEeSy), Université Grenoble-Alpes, Grenoble, France.

\section{Received: 8 February 2019 Accepted: 18 June 2019}

Published online: 15 July 2019

\section{References}

1. Jeschke P, Nauen R, Beck ME. Nicotinic acetylcholine receptor agonists: a milestone for modern crop protection. Angew Chem Int Ed Eng. 2013; 52(36):9464-85.

2. Bass C, Denholm I, Williamson MS, Nauen R. The global status of insect resistance to neonicotinoid insecticides. Pestic Biochem Physiol. 2015;121: 78-87.

3. Yadouleton AWM, Asidi A, Djouaka RF, Braïma J, Agossou CD, Akogbeto MC. Development of vegetable farming: a cause of the emergence of insecticide resistance in populations of Anopheles gambiae in urban areas of Benin. Malar J. 2009;8(1):103.

4. Chouaïbou MS, Fodjo BK, Fokou G, Allassane OF, Koudou BG, David JP, et al. Influence of the agrochemicals used for rice and vegetable cultivation on insecticide resistance in malaria vectors in southern Côte d'Ivoire. Malar J. 2016;15(1):426

5. Abuelmaali SA, Elaagip AH, Basheer MA, Frah EA, Ahmed FT, Elhaj HF, et al. Impacts of agricultural practices on insecticide resistance in the malaria vector Anopheles arabiensis in Khartoum state, Sudan. PLoS One. 2013;8: e80549. https://doi.org/10.1371/journal.pone.0080549.

6. Luc DS, Benoit A, Laurette D, Michel M. Indirect evidence that agricultural pesticides select for insecticide resistance in the malaria vector Anopheles gambiae. J Vector Ecol. 2016;41(1):34-40.

7. Nkya TE, Poupardin R, Laporte F, Akhouayri I, Mosha F, Magesa S, et al. Impact of agriculture on the selection of insecticide resistance in the malaria vector Anopheles gambiae: a multigenerational study in controlled conditions. Parasit Vectors. 2014;7(1):480.

8. Müller P, Chouaïbou M, Pignatelli P, Etang J, Walker ED, Donnelly MJ, et al Pyrethroid tolerance is associated with elevated expression of antioxidants and agricultural practice in Anopheles arabiensis sampled from an area of cotton fields in northern Cameroon. Mol Ecol. 2008;17(4):1145-55.

9. Fodjo BK, Koudou BG, Tia E, Saric J, N'dri PB, Zoh MG, et al. Insecticides resistance status of an. Gambiae in areas of varying agrochemical use in Côte D'Ivoire. Biomed Res Int. 2018;2018:2874160.

10. Brogdon WG, McAllister JC. Simplification of adult mosquito bioassays through use of time-mortality determinations in glass bottles. J Am Mosq Control Assoc. 1998:14(2):159-64.

11. Horstmann S. Modified CDC bottle assay with single active ingredients of Fludora ${ }^{\circledast}$ fusion. 2016

12. Collins FH, Mendez MA, Rasmussen MO, Mehaffey PC, Besansky NJ, Finnerty $\checkmark$. A ribosomal RNA gene probe differentiates member species of the Anopheles gambiae complex. Am J Trop Med Hyg. 1987;37(1):37-41.

13. Santolamazza F, Mancini E, Simard F, Qi Y, Tu Z, della Torre A. Insertion polymorphisms of SINE200 retrotransposons within speciation islands of Anopheles gambiae molecular forms. Malar J. 2008;7(1):163.

14. WHO. Test procedures for insecticide resistance monitoring in malaria vector mosquitoes. Geneva: World Health Organization; 2013. ISBN: 978924 1511575

15. Abbott WS. A method of computing the effectiveness of an insecticide. J Econ Entomol. 1925:18(2):265-7.

16. Lines JD. Do agricultural insecticides select for insecticide resistance in mosquitoes? A look at the evidence. Parasitol Today. 1988:4(7):17-20.

17. Arthropod Pesticide Resistance Database / Michigan State University. https:// www.pesticideresistance.org/search.php. Accessed 14 Jan 2019.

18. Liu Z, Williamson MS, Lansdell SJ, Denholm I, Han Z, Millar NS. A nicotinic acetylcholine receptor mutation conferring target-site resistance to imidacloprid in Nilaparvata lugens (brown planthopper). Proc Natl Acad Sci U S A. 2005:102(24):8420-5.

19. Shimomura M, Yokota M, Ihara M, Akamatsu M, Sattelle DB, Matsuda K. Role in the selectivity of neonicotinoids of insect-specific basic residues in loop $\mathrm{D}$ of the nicotinic acetylcholine receptor agonist binding site. Mol Pharmacol. 2006;70(4):1255-63.

20. Crossthwaite AJ, Rendine S, Stenta M, Slater R. Target-site resistance to neonicotinoids. J Chem Biol. 2014;7(4):125-8.

21. Tiwari S, Mann RS, Rogers ME, Stelinski LL. Insecticide resistance in field populations of Asian citrus psyllid in Florida. Pest Manag Sci. 2011;67(10): 1258-68.

22. Wang KY, Liu TX, Yu CH, Jiang XY, Yi MQ. Resistance of Aphis gossypii (Homoptera: Aphididae) to fenvalerate and imidacloprid and activities of detoxification enzymes on cotton and cucumber. J Econ Entomol. 2002; 95(2):407-13.

23. Puinean AM, Foster SP, Oliphant L, Denholm I, Field LM, Millar NS, et al. Amplification of a cytochrome $\mathrm{P} 450$ gene is associated with resistance to neonicotinoid insecticides in the aphid Myzus persicae. PLoS Genet. 2010; 6(6):e1000999.

24. Karunker I, Benting J, Lueke B, Ponge T, Nauen R, Roditakis E, Vontas J, et al. Over-expression of cytochrome P450 CYP6CM1 is associated with high resistance to imidacloprid in the $\mathrm{B}$ and $\mathrm{Q}$ biotypes of Bemisia tabaci (Hemiptera: Aleyrodidae). Insect Biochem Mol Biol. 2008;38(6):634-44.

25. Jones CM, Daniels M, Andrews M, Slater R, Lind RJ, Gormana K, et al. Agespecific expression of a P450 monooxygenase (CYP6CM1) correlates with neonicotinoid resistance in Bemisia tabaci. Pestic Biochem Physiol. 2011; 101(1):53-8.

26. Yang $N$, Xie $W$, Jones $C M$, Bass $C$, Jiao $X$, Yang $X$, et al. Transcriptome profiling of the whitefly $B$ emisia tabaci reveals stage-specific gene expression signatures for thiamethoxam resistance. Insect Mol Biol. 2013:22(5):485-96.

27. Karatolos N, Williamson MS, Denholm I, Gorman K, Bass C. Over-expression of a cytochrome P450 is associated with resistance to pyriproxyfen in the greenhouse whitefly Trialeurodes vaporariorum. PLoS One. 2012;7(2):31077. 
28. Bass C, Carvalho RA, Oliphant L, Puinean AM, Field LM, Nauen R, et al. Overexpression of a cytochrome P450 monooxygenase, CYP6ER1, is associated with resistance to imidacloprid in the brown planthopper, Nilaparvata lugens. Insect Mol Biol. 2011;20(6):763-73.

29. Zhao JZ, Bishop BA, Grafius EJ. Inheritance and synergism of resistance to imidacloprid in the Colorado potato beetle (Coleoptera: Chrysomelidae). J Econ Entomol. 2000;93(5):1508-14.

30. Chouaïbou M, Kouadio FB, Tia E, Djogbenou L. First report of the east African kdr mutation in an Anopheles gambiae mosquito in Côte d'Ivoire. Wellcome Open Res. 2017;2:8.

31. NEPAD. African agriculture, transformation and outlook. Midrand: The New Partnership for Africa's Development (NEPAD); Africa Union (AU); 2013. p. 72.

Ready to submit your research? Choose BMC and benefit from:

- fast, convenient online submission

- thorough peer review by experienced researchers in your field

- rapid publication on acceptance

- support for research data, including large and complex data types

- gold Open Access which fosters wider collaboration and increased citations

- maximum visibility for your research: over $100 \mathrm{M}$ website views per year

At BMC, research is always in progress.

Learn more biomedcentral.com/submissions 